\title{
INTEGRATION OF AUGMENTED REALITY IN BUILDING INFORMATION MODELING: APPLICABILITY AND PRACTICALITY
}

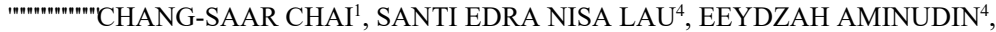 \\ SIAW-CHUING LOO ${ }^{\natural}$, MASOUD GHEISARI ${ }^{\natural}$ \& MOHAMED ABDELRAOUF ABDALRAHMAN \\ ${ }^{1}$ Faculty of Engineering, Computing and Science, Swinburne University of Technology Sarawak, Malaysia \\ ${ }^{\square}$ Department of Structure and Materials, School of Civil Engineering, Faculty of Engineering, \\ Universiti Teknologi Malaysia, Malaysia \\ ${ }^{\square}$ Centre of Building, Construction and Tropical Architecture, Faculty of Built Environment, \\ University of Malaya, Malaysia \\ ${ }^{\square}$ Rinker School of Construction Management, University of Florida, USA
}

\begin{abstract}
The digitalisation of the construction industry fuels the application of sophisticated virtual product models. Concerning current measures in construction project management, the acquisition of sufficient data and information hinders the project execution. However, the application of fully automated techniques within the construction industry is not yet a common practice. This explains the slow rate of digital growth in construction. This study is aiming to investigate the adoption of augmented reality (AR) using building information modeling (BIM) content in the construction industry. In order to achieve the aim, a questionnaire survey is conducted across four countries, namely Malaysia, Egypt, Saudi Arabia and Turkey. A comparison of AR-BIM adoption behaviour among these four countries is established. The findings show that AR has great potential to be adopted in the construction industry, provided that the obstacles hindering the adoption are resolved. Among the four countries, Malaysians are optimistic to the AR-BIM adoption. This might be due to the great effort in promoting technology adoption which is done by the Malaysian government through the Construction Industry Transformation Plan (CITP). A software architecture framework of AR-BIM is developed using the Unity and BIM Model workflow. This study is important to serve as a guideline to practitioners in adopting AR-BIM. Also, it helps the decision makers to emphasize which technology adoption criteria is to be focused on in enhancing AR-BIM adoption in respective organizations.
\end{abstract}

Keywords: augmented reality (AR), building information modelling (BIM).

\section{INTRODUCTION}

The construction industry today are changing towards an organized and sustainable construction process pathway through adopting new technologies that able to increase efficiency of construction process. Building information modeling (BIM) has proved its value in enhancing project information throughout the project lifecycle [1]. It allows a proper planning among the architect, engineer and contractor (AEC) to reduce conflict between the players and increase communication efficiency. This is essentially important due to the nature of construction works are mostly fragmented, resulted in lack of respect and trust among the stakeholders and poor project management.

BIM is a three-dimensional (3D) model based process for developing the building projects with the related properties [2]. Eventually BIM is not a software, it is a platform to integrate different information into a single model. There is high possibility that BIM will be part of the construction standard in near future. This can be seen from the BIM submission is made compulsory in several countries like Singapore, Denmark, Finland, United Kingdom, Hong Kong, South Korea and others. The content creation in BIM models are not limited to be managed through desktop facilities, it is further extended to cloud computing to enable BIM 
platform users to enhance BIM information at anywhere and anyplace. Furthermore, it is able to be further integrated in digital twinning where the models can be presented in different form of digital devices including augmented reality, virtual reality, mix reality, 3D printing and many others.

Augmented reality (AR) is not a new digital approach, however the application of AR is mostly related in gaming industry. Although it is now constantly venturing in different sectors including construction sector but the potential applicability and practicality of AR-BIM in construction industry remain as the biggest challenge. Therefore, this paper is taken the initiative to examine the applicability and practicality of AR-BIM in construction industry. The feasibility study of AR-BIM is conducted across four countries and a workflow of ARBIM modeling will be developed.

\section{AUGMENTED REALITY INTEGRATION IN BUILDING INFORMATION MODELLING}

BIM is perceived as a rising innovation that can, on a very basic level, enhance the project delivery. Nevertheless, the BIM advantages still cannot seem to be accomplished. The incorporation of different technologies with BIM must integrate with suitable managerial methods and strategies. It is proposed that this is essential in minimizing the number of challenges of BIM. Various sorts of management and contract organization are, as a result, required to encourage the diverse levels of BIM adoption and precocity [3].

From the various literature, there are less research on the BIM utilization to support fieldwork, likewise, collaborative information sharing and on-site coordination planning. Besides, there are also limited research on BIM usage in the hands of workers in construction sites [4]. The implication of that fact is computer generated dimensions, textures, spatial location, and environment, provide a very restricted level of "realism" because of the shortage of sensory feedback and thus the lack of ability to afford perceptual and cognitive benefits. The computerized building data in BIM is liable to an absence of an association between the virtual and real world, which to some degree, prevents the gross grasp of digitized project information. This leads to limitations to the real-time incorporation of BIM to the site conditions and the interaction between the field crew and BIM. As per Wang et al. [5], the integration between BIM and cloud-based collaborative platforms will allow clients and stakeholders to gather instant data and feedback on their project designs and plans, by the usage of their smartphones or tablets which can be achieve by integrating augmented reality in BIM.

Augmented reality (AR) is a live direct or indirect view of a physical real-world environment [6]. The 3D and 4D objects are made by computer graphic using virtual reality (VR) technology. The integration of AR and BIM (AR-BIM) provides a collaborative platform to help in managing and exchanging all the project data, which can be supported by mobile devices and tablets. Building Information models can be visualized on mobile phones and tablets via AR to help the construction stakeholders throughout the process of construction to improve the work quality [7]. Table 1 shows the potential application of ARBIM in construction industry.

In the present construction industry practices, BIM and AR frameworks can recognize the interconnection. The AR-BIM systems enhance the interconnection between work tasks as well as improve the existing intricacy and the interconnection on site. The framework merging between AR and BIM allows the participants to visualize an immersive view into reality and view the as-planned information onto the as-built environment and relieve the workload in the participant mind. As AR and BIM models are viewed in reality, the platform 
Table 1: Potential application of AR-BIM in the construction industry.

\begin{tabular}{|l|l|l|}
\hline Potential application & Description & References \\
\hline Setting out & $\begin{array}{l}\text { Reference points could be showed using AR at } \\
\text { a time by referencing to just one point. }\end{array}$ & {$[8],[9]$} \\
\hline Excavation & $\begin{array}{l}\text { Desired depth of the excavation is showed } \\
\text { using AR, replaced the original stakes method. }\end{array}$ & {$[8],[10]$} \\
\hline Positioning & $\begin{array}{l}\text { Precise location of the construction elements } \\
\text { are showed using AR. }\end{array}$ & {$[8],[11]$} \\
\hline Inspection & $\begin{array}{l}\text { Difference between as-built condition and as- } \\
\text { planned model are provided during inspection. }\end{array}$ & {$[8],[12]$} \\
\hline Communication & $\begin{array}{l}\text { Visualization provided to prevent } \\
\text { miscommunication, especially during } \\
\text { commenting, coordination and strategizing. }\end{array}$ & {$[5],[8]$} \\
\hline
\end{tabular}

provide precise data context as the input of data stream is managed by backend support team, channeling the information (virtual models) to the users at construction site including workers. Through this, the workers will be able to observe and see the progress of the work tasks and the differences between the current and the future work progress [5].

The traditional construction practices of having enormous number of drawings and index sheet in the site offices are waste of resources [13]. This can be solved by integrating AR and BIM where the users able to access the drawing at anytime and anywhere. Considering that AR by nature includes the human sensations with both genuine and virtual data sources. It is additionally found that AR ought to be universal and cooperate with exact situating advances, for example, laser indicating. BIM gives moderately static and pre-characterized information and data. AR gives localization of reality, considering vision-based AR is a value added. AR might be a simple access interface, but it may possibly change how site manager, workers, etc change the entire management workflow in the industry [14].

\section{RESEARCH METHODOLOGY}

This study utilized both quantitative and qualitative approaches. The quantitative approach utilized questionnaire survey to collect data on the applicability of AR-BIM in construction industry meanwhile qualitative approach involved developing of experimental work with AR-BIM workflow. The questionnaire survey data will be analyzed through Principle Component Analysis (PCA). The reliability and sampling adequacy of the data will be tested using Cronbach's Alpha and Kaiser-Meyer-Olkin (KMO) and Bartlett's Test of Sphericity. Both questionnaire reliability and sampling adequacy threshold are set at 0.7 . The Cronbach's Alpha of the study is recorded at 0.801 meanwhile $\mathrm{KMO}$ is at 0.727 , indicating a high reliability and high adequacy instrument.

The questionnaires are distributed across four countries, namely Egypt, Malaysia, Turkey and Saudi Arabia. The similarity among these four countries lay on the Level 1 BIM implementation in the respective country. However, there are significant differences in the government policies related to BIM implementation. 400 sets of questionnaire surveys were sent to four countries; there were 214 respondents who responded to the questionnaire, however, there were only 152 valid data, indicating $38 \%$ of the response rate. From the 152 respondents, there were 27 respondents from Egypt, 43 from Malaysia, 43 from Turkey and 29 from Saudi Arabia. 
Table 2: Cross-tabulation of respondent backgrounds.

\begin{tabular}{|c|c|c|c|c|c|c|}
\hline \multicolumn{7}{|c|}{$\begin{array}{l}\text { Respondent position/Respondent country of residence/ } \\
\text { Respondent years of experience }\end{array}$} \\
\hline \multirow{2}{*}{\multicolumn{2}{|c|}{ Respondent years of experience }} & \multicolumn{4}{|c|}{ Working location } & \multirow[b]{2}{*}{ Total } \\
\hline & & Egypt & Malaysia & Turkey & $\begin{array}{l}\text { Saudi } \\
\text { Arabia }\end{array}$ & \\
\hline \multirow{6}{*}{$\begin{array}{l}\text { Less than } 5 \\
\text { years }\end{array}$} & \multirow{2}{*}{ Civil Engineer } & 5 & 6 & 3 & 2 & 16 \\
\hline & & $31.25 \%$ & $37.50 \%$ & $18.75 \%$ & $12.50 \%$ & $100.00 \%$ \\
\hline & \multirow{2}{*}{ Architecture } & 2 & 4 & 7 & 3 & 16 \\
\hline & & $12.50 \%$ & $25.00 \%$ & $43.75 \%$ & $18.75 \%$ & $100.00 \%$ \\
\hline & \multirow{2}{*}{ Project Manager } & 1 & 1 & 1 & 1 & 4 \\
\hline & & $25.00 \%$ & $25.00 \%$ & $25.00 \%$ & $25.00 \%$ & $100.00 \%$ \\
\hline \multirow{8}{*}{$5-10$ years } & \multirow{2}{*}{ Civil Engineer } & 13 & 10 & 17 & 8 & 48 \\
\hline & & $27.08 \%$ & $20.83 \%$ & $35.42 \%$ & $16.67 \%$ & $100.00 \%$ \\
\hline & \multirow{2}{*}{ Architecture } & 5 & 7 & 5 & 1 & 18 \\
\hline & & $27.78 \%$ & $38.89 \%$ & $27.78 \%$ & $5.56 \%$ & $100.00 \%$ \\
\hline & \multirow{2}{*}{ Project Manager } & 1 & 2 & 2 & 5 & 10 \\
\hline & & $10.00 \%$ & $20.00 \%$ & $20.00 \%$ & $50.00 \%$ & $100.00 \%$ \\
\hline & \multirow{2}{*}{ BIM Coordinator } & 5 & 7 & 3 & 3 & 18 \\
\hline & & $27.78 \%$ & $38.89 \%$ & $16.67 \%$ & $16.67 \%$ & $100.00 \%$ \\
\hline \multirow{6}{*}{$\begin{array}{l}\text { More than } \\
10 \text { years }\end{array}$} & \multirow{2}{*}{ Civil Engineer } & 2 & 1 & 1 & 2 & 6 \\
\hline & & $33.33 \%$ & $16.67 \%$ & $16.67 \%$ & $33.33 \%$ & $100.00 \%$ \\
\hline & \multirow{2}{*}{ Architecture } & 1 & 1 & 1 & 3 & 6 \\
\hline & & $16.67 \%$ & $16.67 \%$ & $16.67 \%$ & $50.00 \%$ & $100.00 \%$ \\
\hline & \multirow{2}{*}{ Project Manager } & 2 & 4 & 3 & 1 & 10 \\
\hline & & $20.00 \%$ & $40.00 \%$ & $30.00 \%$ & $10.00 \%$ & $100.00 \%$ \\
\hline & Total & 37 & 43 & 43 & 29 & 152 \\
\hline
\end{tabular}

\section{RESULT AND DISCUSSIONS}

\subsection{Applicability}

Principle Component Analysis (PCA) on potential application of AR during construction were tabulated in Table 3. Significantly, the AEC industry is very confident in using AR for positioning purpose, but doubt on the applicability of AR for excavation and inspection, especially for Egypt and Saudi Arabia. Current practice using bare eyes to identify the location for positioning. However, such practice might cause deviation between as-built and as-planned situation, especially when precise positioning is required. Utilizing AR for precise positioning could significantly increase the accuracy and efficiency. Besides, the industry seems to have sufficient trust in the application of AR for on-site communication and setting out, as both of these factors are having relatively high factor loading. As compared among the four countries, both Malaysia and Turkey are confidence to handle the implementation of AR-BIM in the construction. This can be seen from the high factor loadings of using ARBIM in setting out, excavation, positioning, inspection and communication. 
Table 3: Potential application of AR during construction.

\begin{tabular}{|l|c|c|c|c|}
\hline $\begin{array}{l}\text { Potential application of AR during } \\
\text { construction }\end{array}$ & \multicolumn{4}{|c|}{ Factor loading } \\
\hline & Egypt & Malaysia & Turkey & $\begin{array}{c}\text { Saudi } \\
\text { Arabia }\end{array}$ \\
\hline $\begin{array}{l}\text { Setting out, show all desired references points } \\
\text { virtually }\end{array}$ & 0.831 & 0.849 & 0.833 & 0.816 \\
\hline $\begin{array}{l}\text { Excavation, show the desired excavating } \\
\text { depth virtually }\end{array}$ & & 0.722 & 0.702 & \\
\hline $\begin{array}{l}\text { Positioning, show all the precise location } \\
\text { virtually }\end{array}$ & 0.952 & 0.863 & 0.938 & 0.896 \\
\hline $\begin{array}{l}\text { Inspection, show the difference between as- } \\
\text { planned and as-built condition }\end{array}$ & & 0.845 & 0.973 & \\
\hline $\begin{array}{l}\text { Communication, as it synchronize mental } \\
\text { models }\end{array}$ & 0.906 & 0.858 & 0.866 & 0.875 \\
\hline
\end{tabular}

Table 4: Challenges of AR-BIM adoption.

\begin{tabular}{|l|c|c|c|c|}
\hline Challenges of AR-BIM adoption & \multicolumn{4}{|c|}{ Factor loading } \\
\hline & Egypt & Malaysia & Turkey & $\begin{array}{c}\text { Saudi } \\
\text { Arabia }\end{array}$ \\
\hline Lack of external incentives & & 0.862 & 0.726 & \\
\hline Staff buy-in & 0.859 & 0.858 & 0.866 & 0.825 \\
\hline High software cost & 0.864 & 0.732 & 0.841 & 0.810 \\
\hline Additional cost for hardware upgrade & 0.882 & 0.779 & 0.759 & 0.766 \\
\hline Insufficient training time & & 0.863 & 0.811 & 0.753 \\
\hline Insufficient training resources & & 0.895 & 0.834 & 0.749 \\
\hline Risk of losing intellectual properties & 0.861 & 0.761 & 0.853 & \\
\hline
\end{tabular}

While looking at the challenges for AR-BIM adoption as shown in Table 4, the industry seems to disagree that lack of external incentives and training issues had hurdled them for the adoption for Egypt and Saudi Arabia. Their main concern is on financial issues. While Small and Medium Enterprise (SME) might have limited turnover for software and hardware improvement, those from well-established company might also feel challenging to request additional budget from financial department, who had limited knowledge and awareness on BIM. Meanwhile four countries respondents agreed on the challenges of staff buy-in, high software cost and additional cost for hardware upgrade.

As shown in Table 5, respondents seem to have less confident when mentioned about the easiness to learn AR-BIM and its impact to positive company profit generation except for Turkey. Meanwhile Malaysia is the only country that able to perform AR-BIM without aid from the expert. This might be due to the generation $\mathrm{Z}$ in Malaysia are keen in digital 
Table 5: Elements defining AR-BIM acceptance.

\begin{tabular}{|l|c|c|c|c|}
\hline Elements defining AR-BIM acceptance & \multicolumn{5}{|c|}{ Factor loading } \\
\hline & Egypt & Malaysia & Turkey & $\begin{array}{c}\text { Saudi } \\
\text { Arabia }\end{array}$ \\
\hline This can improve my job quality & 0.824 & 0.865 & 0.853 & 0.838 \\
\hline This can improve my productivity & 0.856 & 0.833 & 0.878 & 0.855 \\
\hline This can enhance my effectiveness & 0.724 & 0.844 & 0.812 & 0.808 \\
\hline This can increase my company's profit & & & 0.725 & \\
\hline This help me to access more information & 0.802 & 0.792 & & 0.880 \\
\hline This help me in decision making & 0.768 & 0.785 & 0.872 & 0.716 \\
\hline $\begin{array}{l}\text { This can improve communication among the } \\
\text { project team }\end{array}$ & 0.853 & 0.719 & 0.787 & 0.751 \\
\hline This is easy to learn & & & 0.709 & \\
\hline $\begin{array}{l}\text { This gives a clear and understandable } \\
\text { interface }\end{array}$ & & 0.847 & 0.859 & 0.732 \\
\hline This can be used without the aid from expert & & 0.774 & & \\
\hline
\end{tabular}

technologies and these generations are given more opportunities in developing technologies knowledge. Besides, the respondents from the four countries agreed that AR-BIM is able to improve their job quality, productivity, effectiveness, decision making and communication. This is mostly due to the ability of AR and BIM that integrated the project information into one model, presented through a single virtual model. However, Turkey professionals disagreed that the AR-BIM given opportunity for the user to access more information. This can be seen that the factor is eliminated during PCA analysis. In Turkish opinion, AR-BIM might able to integrate the information into one single model, presented through AR form in handheld devices to enhance the efficiency of project execution. But there are information that could not be integrated in AR model at the current stage for example the costing and scheduling information. Eventually the current AR-BIM in the market is able to present the virtual model only without integrating the $4 \mathrm{D}, 5 \mathrm{D}$ and $6 \mathrm{D}$ information.

\subsection{Practicality}

BIM information can be intuitively visualized via AR to guide construction workers through the construction of actual buildings and improve the quality of their work (Wang et al. [7]). There are several methods to integrate BIM content into AR platform, this study utilized gaming platform to perform the integration function. Obviously, gaming industry is the pioneer in VR as well as in AR. Unity 3D software is a powerful cross-platform 3D engine and it lets the user target virtual reality devices directly from Unity. The Vuforia AR Extension for Unity enables vision detection and tracking functionality within the Unity and allows developers to create AR applications and games easily for smartphones and tablets. A software architecture is designed as shown in Fig. 1.

From Fig. 1, the AR-BIM development involved three main stages. The first stage is the back-end stage where the administrative work including admin management, record activity, setting, security and import 3D model are done in this stage. The 3D model is developed from 


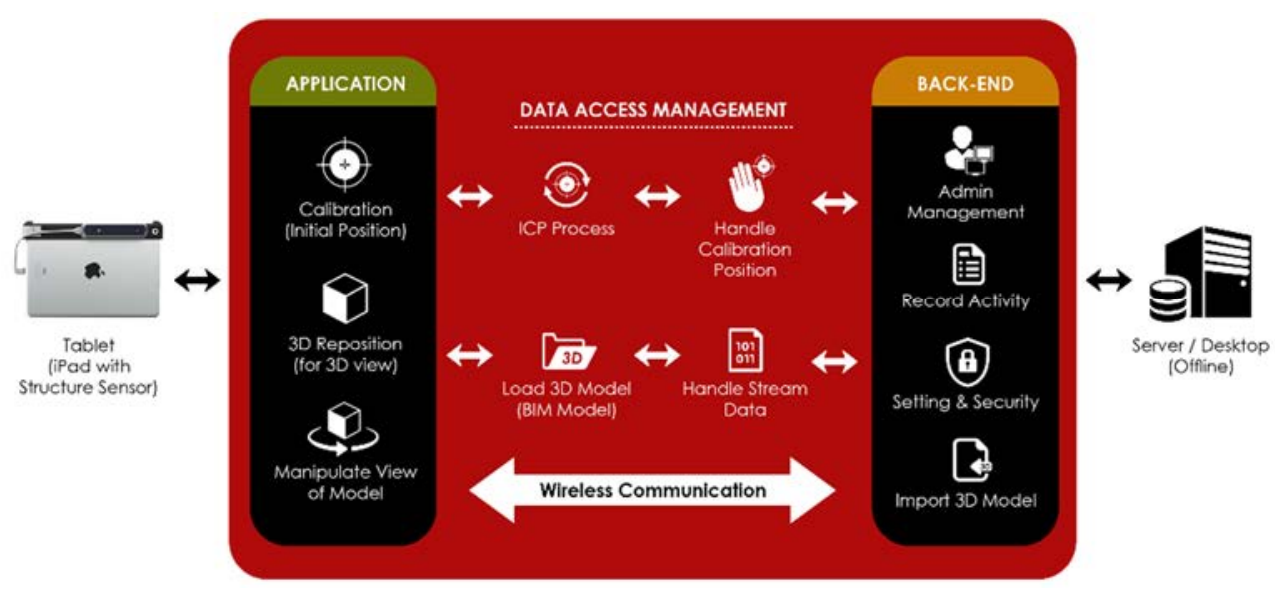

Figure 1: Software architecture for AR-BIM.

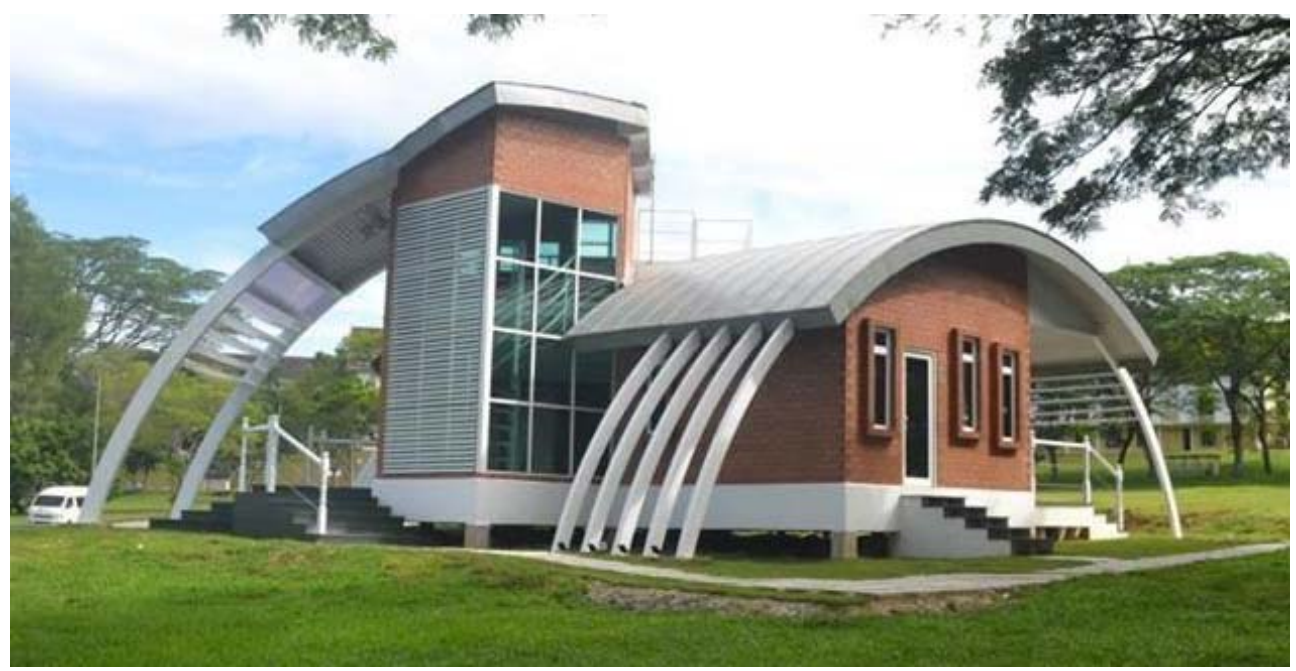

Figure 2: Selected building.

an actual building as shown in Fig. 2. The BIM virtual model is established through Revit 2017 (Fig. 3). The 3D model is then gone through data access management stage where the positioning of the model will be calibrated accordingly. This stage also important to handle stream data, ICP process and loading of 3D model in the system.

The last stage of the AR-BIM development is on the application stage. This stage is important to calibrate the location of the virtual BIM model with the actual location in the reality. This is to ensure that the walkthrough experience of the users in the virtual model will be exactly the same in the reality. From Fig. 4, the preliminary integration of AR-BIM in the tablet device is successful. 


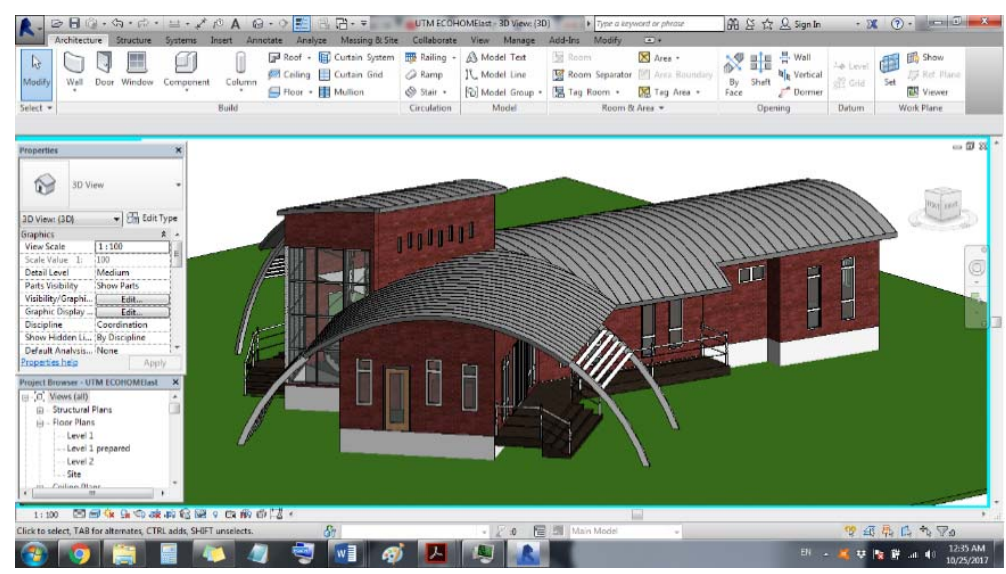

Figure 3: BIM model for selected building.

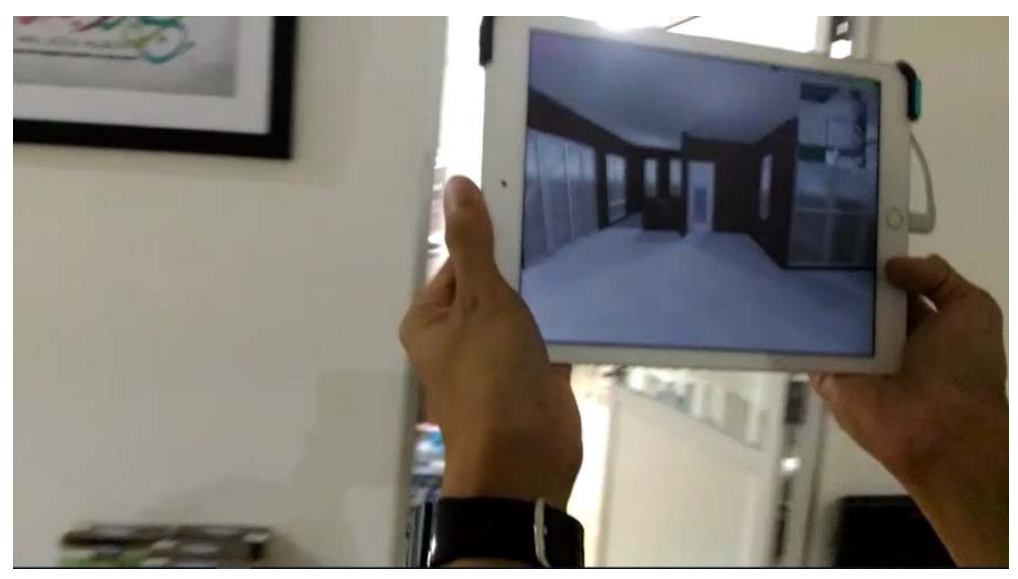

Figure 4: AR-BIM integration.

The virtual 3D model shown in the tablet (in Fig. 4) indicated the walkthrough experience of AR-BIM. The entire AR-BIM platform is done by using Unity, Vuforia and C\# programming knowledge. However, the limitation of the above preliminary integration is the positioning of reality experience in the virtual model. The ideal AR-BIM model should be able to integrate both virtual model and reality in a same platform, but the Fig. 4 tablet shows the virtual model only. This is mainly due to the incomplete $\mathrm{C} \#$ programming in the Unity platform. Although the AR-BIM model is not perfect but it proven the digital construction concept that AR integration in BIM is workable. From the study, the AR-BIM is most useful for the facility management team in handling operation and maintenance activities. The 3D model in the tablet gives clear indication of underlying service inside the wall or beneath the floor. Besides, the contribution of the AR-BIM can be seen from the education aspects. The industry training for the young engineers no longer needed to be present at construction site, but it can be conducted in office using the AR-BIM model. This significantly reduces the accident risk for the young engineers. 


\section{CONCLUSION}

This paper had identified the importance, acceptance criteria and AR-BIM application in the construction industry. When identifying the perceived value of AR during construction, the industry are having highest confident on the applicability of AR during setting out, positioning and communication. Meanwhile, Malaysia AEC industry do agree on most of the potential application of AR-BIM in the industry. This is mostly related to the Malaysian government initiative in enhancing construction productivity through the Construction Industry Transformation Plan (CITP) and the liberalization of professional services in the country. Malaysians are urged to adopt innovative technologies to maintain their competitiveness in the market share. With sufficient understanding on AR and BIM, the industry members should have a direction for their future development to secure or even improve their competitiveness in local and global markets.

\section{ACKNOWLEDGEMENT}

This work was supported by UoRM-FRGS (HM102600), Ministry of Education Malaysia.

\section{REFERENCES}

[1] Czmoch, I. \& Pękala, A., Traditional design versus BIM based design. Procedia Engineering, 91(TFoCE), pp. 210-215, 2014.

[2] Gheisari, M. \& Irizarry, J., Investigating human and technological requirements for successful implementation of a BIM-based mobile augmented reality environment in facility management practices. Facilities, 34(1/2), pp. 69-84, 2016.

[3] Singh, V., BIM and systemic ICT innovation in AEC: Perceived needs and actor's degrees of freedom. Construction Innovation, 14(3), pp. 292-306, 2014.

[4] Hou, L. et al., Using augmented reality to facilitate piping assembly: An experimentbased evaluation. Journal of Computing in Civil Engineering, 29(1), 05014007, 2013.

[5] Wang, X., Truijens, M., Hou, L., Wang, Y. \& Zhou, Y., Integrating augmented reality with building information modeling: Onsite construction process controlling for liquefied natural gas industry. Automation in Construction, 40(2014), pp. 96-105, 2014.

[6] Agarwal, S., Review on application of augmented reality in civil engineering. International Conference on Interdisciplinary Research in Engineering and Technology.

[7] Wang, X., Truijens, M., Hou, L. \& Wang, Y., Application of collaborative mobile system in AR-based visualization, data storage and manipulation. International Conference on Cooperative Design, Visualization and Engineering, Springer: Berlin, Heidelberg, pp. 221-226, 2013.

[8] Shin, D.H. \& Dunston, P.S., Identification of application areas for augmented reality in industrial construction based on technology suitability. Automation in Construction, 17(2008), pp. 882-894, 2008.

[9] Siu, M.F. \& Lu, M., Bored pile construction visualization by enhanced production-line chart and augmented-reality photos. Proceedings of the 10th International Conference on Construction Applications of Virtual Reality (CONVR), Sendai, Japan, 4-5 Nov., pp. 165-174, 2010.

[10] Bentley, Augmented reality for subsurface utilities: Further improving perception, 2012.

https://communities.bentley.com/other/old_site_member_blogs/bentley_employees/ b/stephanecotes_blog/archive/2012/06/18/augmented-reality-for-subsurface-utilitiesfurther-improving-perception. 
[11] Roberts, G.W., Evans, A., Dodson, A.H., Densby, B., Cooper, S. \& Hollands, R., The use of augmented reality, GPS and INS for subsurface data visualisation. XXII FIG International Congress, 19-26 Apr., Washington, DC: International Federation of Surveyors, 2002.

[12] Hammad, A., Garrett Jr., J.H. \& Karimi, H.A., Potential of mobile augmented reality for infrastructure field tasks. Applications of Advanced Technologies in Transportation, 5-7 Aug., Boston, Massachusetts: American Society of Civil Engineers (ASCE), pp. 425-432, 2002.

[13] Moum, A., Design team stories: Exploring interdisciplinary use of 3D object models in practice. Automation in Construction, 19(5), pp. 554-569, 2010.

[14] Wang, X. \& Love, P.E., BIM+ AR: Onsite information sharing and communication via advanced visualization. Computer Supported Cooperative Work in Design (CSCWD), 2012 IEEE 16th International Conference on Computer Supported Cooperative Work in Design (CSCWD), IEEE, pp. 850-855, 2012. 